Selected Papers of the Fourth Conference on

\title{
East Asia and Western Pacific Meteorology and Climate
}


WORLD SCIENTIFIC SERIES ON METEOROLOGY OF EAST ASIA

\author{
Editorial Board \\ C.-P. Chang, Naval Postgraduate School (Chair) \\ Tai-Jen George Chen, National Taiwan University \\ Yihui Ding, National Climate Center of China \\ In-Sik Kang, National Seoul University \\ Ngar-Cheung Gabriel Lau, Princeton University \\ William K. M. Lau, NASA Goddard Space Flight Center \\ Akimasa Sumi, University of Tokyo \\ Bing Wang, University of Hawaii \\ Guoxiong Wu, Chinese Academy of Sciences \\ Michio Yanai, University of California, Los Angeles \\ Tetsuzo Yasunari, Tsukuba University
}




\section{WORLD SCIENTIFIC SERIES ON \\ METEOROLOGY OF EAST ASIA}

Vol. 1

Selected Papers of the Fourth Conference on

\section{East Asia and Western Pacific Meteorology and Climate}

Hangzhou, China October 26-28, 1999

Editors

C.-P. Chang

Naval Postgraduate School

Guoxiong $\mathbf{W u}$

Chinese Academy of Scienced

Ben Jou

National Taiwan University

C. Y. Lam

Hong Kong Observatory 


\section{Published by}

World Scientific Publishing Co. Pte. Ltd.

P O Box 128, Farrer Road, Singapore 912805

USA office: Suite 1B, 1060 Main Street, River Edge, NJ 07661

UK office: 57 Shelton Street, Covent Garden, London WC2H 9HE

\section{British Library Cataloguing-in-Publication Data}

A catalogue record for this book is available from the British Library.

\section{EAST ASIA AND WESTERN PACIFIC METEOROLOGY AND CLIMATE \\ World Scientific Series on Meteorology of East Asia Vol. 1 \\ Copyright $\odot 2002$ by World Scientific Publishing Co. Pte. Ltd.}

All rights reserved. This book, or parts thereof, may not be reproduced in any form or by any means, electronic or mechanical, including photocopying, recording or any information storage and retrieval system now known or to be invented, without written permission from the Publisher.

For photocopying of material in this volume, please pay a copying fee through the Copyright Clearance Center, Inc., 222 Rosewood Drive, Danvers, MA 01923, USA. In this case permission to photocopy is not required from the publisher.

ISBN 981-02-4908-X 


\section{FOREWORD}

In the past several decades, considerable progress has been made in the study of the meteorology of East Asia and surrounding areas. The progress arises both from the general advancement in the various fields of atmospheric sciences and the increased international exchanges and related activities that have helped to disseminate a significant amount of knowledge of the meteorology of East Asia to the world scientific community. However, the vast majority of East Asian meteorologists are not English-speaking, and countries within East Asia and surrounding regions have different languages. Thus, communications and exchanges are still hampered by language berriers. The purpose of this new Series on Meteorology of East Asia is to provide a medium to help disseminate the meteorological research in East Asia to the English-speaking world, and to facilitate the exchange among all scientists in this field. As part of the effort, World Scientific Company (WSPC) has agreed to assist in the English editing of manuscripts authored by non-English scientists. It is hoped that this book series will encourage the publication of important advances in East Asian meteorology regardless of the native language of the scientists involved, and thereby bring about increased development of East Asian meteorology and related applications.

The plan for the book series is to publish three types of volumes: selected papers from major conferences, invited review articles, and monogrpahs. Volume 1 is an example of the first type. Volume 2, which is a collection of invited reviews on the East Asian monsoon that will be published next, is of the second type. Other volumes of all three types are being planned. All fields of meteorology and related sciences are potential topics for the series. Scientists who are interested in contributing to the series, whether as an editor or an author, are encouraged to contact one of the members of the Editorial board (listed in inside cover).

I wish to thank all members of the Editorial board, from both East Asia and the U.S., for their devotion to the purpose of this endeavor; and to Professor K. K. Phua, Chairman cum Editor-in-Chief of WSPC, whose vision on the importance of meteorological sciences for the 
large geographic area and large population of East Asia and the surrounding regions has led to the initiation of this book series.

Chih-Pei Chang

Department of Meteorology Naval Postgraduate School Monterey, California 


\section{PREFACE}

When the participants of the Fourth Conference on East Asia and Western Pacific Meteorology and Climate assembled in Hangzhou 26-28 October 1999, they were in effect celebrating the tenth anniversary of an endeavor that had a modest beginning in Hong Kong. The original idea for such a conference germinated in Hong Kong in 1987-88 during visits by Professors Tao Shiyan and Ding Yihui of the Chinese Academy of Sciences, Professor Ching-Yen Tsay of National Taiwan University, and Professor C.-P. Chang of Naval Postgraduate School. They noted that there were language and geographical barriers that prevented efficient exchanges among scientists studying East Asian meteorology. A bilingual conference would help to reduce these barriers. As the discussion progressed, the idea was warmly embraced by several meteorological community leaders, including Mr. Patrick Sham of Hong Kong Observatory, Dr. Richard Anthes of the University Corporation for Atmospheric Research, and the late Professor Zou Jingmeng, then President of the World Meteorological Organization.

In July 1989 the first conference in this series took place in Hong Kong. It was run with the innovative bilingual approach, which allowed both Chinese- and English-speaking scientists from various regions of East Asia and across the Pacific to come together, and share and discuss their research. It also proved to be an invaluable networking opportunity leading to a rapid growth of interaction and cooperation among a diverse group of scientists in the decade that followed. The enthusiastic participation at the fourth conference as well as the breadth and depth of the presentations were a testimony to this series of conferences coming of age.

The Conference in Hangzhou broke new ground in a number of ways. Sessions on remote sensing, atmospheric physics and chemistry as well as the impact of aircraft emissions on atmospheric composition were introduced, on top of the traditional topics like typhoons, rainstorms, monsoon and climate. Part of the conference was held concurrently with the Symposium on the Severe Rainstorm in 1998, a subject of great interest to meteorologists 
because of its major impact on China in the previous year. The influence of the Conference was thus amplified as it involved some 200 participants during the joint sessions.

This volume contains a collection of selected papers in English although many were originally presented in Chinese during the Conference. We hope that this would make available to the global scientific community the body of knowledge on the various aspects of the meteorology of the East Asia and Western Pacific region as represented by the transactions at the Conference.

The Conference owed its success to the able work of the Organizing Committee headed by Professor Ma Henian. It also had the benefit of financial support from the Natural Science Foundation of China and the University Corporation for Atmospheric Research, U. S. A. Many scientists served as anonymous referees to review and select the papers; they devoted much time to work with the editors in suggesting ways to improve the papers accepted for this publication. Colleagues of the Hong Kong Meteorological Society led by Mr. Y. K. Chan helped with the technical and language editing. The contributions of all these parties are gratefully acknowledged.

Finally, I wish to thank the World Scientific Publishing Company (WSPC), who extended its tradition of publishing the Proceedings of the previous conferences one step further and made this collection of selected papers the first volume of the new World Scientific Series on Meteorology of East Asia.

C Y Lam

Chairman

Hong Kong Meteorological Society 


\section{CONTENTS}

Foreword $\quad$ v

Preface $\quad$ vii

\section{Monsoon Observations}

The Global Monsoon Systems 3

Qingcun ZENG

The SCSMEX/GAME Sounding Networks and the Onset of the 1998 Asian Summer Monsoon

Richard H. JOHNSON and Paul E. CIESIELSKI

Relationship between the Planetary-scale Circulation over East Asia and the Intensity of the South Asian Summer Monsoon

Jianjun XU and Johnny C. L. CHAN

Wind Changes over the Western Pacific

W. Timothy LIU, Xiaosu Xie, Wenqing TANG and Son V. NGHIEM

Interannual Variability of the Timing of the South China Sea Summer

Monsoon Onset and Its Possible Mechanisms

Mong-Ming LU and Yun-Lan CHEN

\section{Climate}

Mechanism of ENSO-Monsoon Interaction during Mature-Decay Phases of ENSO Cycle

Bin WANG, Renguang WU and Xiouhua FU

Impact of Land Surface Processes on Summer Climate

Guoxiong WU, Lan SUN, Yimin LIU, Hui LIU, Shufen SUN and Weiping LI

Impact of ENSO on the Variability of the Asian-Australian Monsoons

Ngar-Cheung $L A U$

Simulation and Prediction of the Regional Climate and Stream-flow in

Taiwan

Ming-Chin WU, Shyh-Chin CHEN and Ching-Pin TUNG 
Summary of COSMIC and Applications to Meteorology and Climate

Richard A. ANTHES and Ying-Hwa KUO

ENSO Occurrence and Anomalies of Sub-surface Ocean Temperature in the

Pacific Warm Pool

LI Chongyin and MU Mingquan

Impact of EI Nino and La Nina on Precipitation and Air Temperature of

Macao

LOU Mei Meng, FONG Soi Kun and HAO I Pan

Relationship between SSTA in the Western Pacific and the June Precipitation in the Mid and the Lower Changjiang Valleys

QIAN Yongfu, WANG Qianqian, WANG Yehong and ZHAO Yuchun

Analysis on Correlation and Causes of Monthly Precipitation and

Droughts/Floods on Both Sides of the Strait from 1951 to 1998

CHEN Juying, WANG Yuhong and XIONG Minquan

Pacific Climate Information and Prediction System (PCIPS) - A New

Project in the U.S. Climate Prediction Center

Yuxiang HE and Anthony G. BARNSTON

\section{Theoretical Studies}

Tropical Tropospheric Biennial Oscillation and ENSO

C.-P. CHANG and Tim LI

Nonlinear Equatorial Kelvin Waves and CISK

Han-Ru CHO

Using the Equivalent Geopotential and Geo-streamfunction to Represent the Pressure Gradient Force in Terrain-following Coordinates over Mountainous Area

Qiu-shi CHEN

\section{Typhoon}

A Statistical Analysis of Typhoons Affecting Taiwan in 1897-1996

Shinn-Liang SHIEH and Shin-Ting WANG

On the Formation of the Hurricane Eye 
Systematic Approach for Tropical Cyclone Track Forecasting with Dynamical Model Selective Consensus

Russell L. ELSBERRY and Lester E. CARR, III

Performance of NOGAPS on the Predictions of Tropical Cyclones Using different Convective Parameterization Schemes

Melinda S. PENG and Timothy F. HOGAN

An Empirical Orthogonal Function Analysis of the Characteristics of Typhoon Rainfall in the vicinity of Taiwan

Tien-Chiang YEH

A Numerical Simulation of the Rainfall Associated with Typhoon Herb

(1996) Using the PSU/NCAR MM5

Chun-Chieh WU, Tzu-Hsiung YEN, Ying-Hwa KUO and Wei WANG

A Preliminary Study of Environmental Momentum Influences on Tropical Cyclone Formation

Cheng-Shang LEE and Chii-Horng LEE

\section{Mesoscale Meteorology}

Convection and Local Circulation under the Influence of Meiyu Front over Northern Taiwan

George Tai-Jen CHEN

Numerical Simulation of the Mesoscale Convective System Observed over Taiwan Strait on 7-8 June 1998

ZHANG Qinghong, Kai-Hon LAU, CHEN Jay-chung and CHEN Shoujun

Doppler Radar Observations of a Quasi-Stationary Mesoscale Convective System and the Associated Vortex

Ben Jong-Dao JOU

Mesoscale Phenomena Observed by Wind Profiler during HUAMEX IOP608 LI Chenguang, LI Yaping and TAO Zuyu

The Application of GPS Data to Synoptic Analysis

YANG Hongmei, XU Baoxiang and ZHOU Xiuji

Test of the Application of Satellite Remote Sensing Land Vegetation Data in Mesoscale Simulation of Heavy Rainfall of Southern China 
Preliminary Study on the Flow Structure of the Strong Precipitation on

June 9, 1998 in Changle Area during HUAMEX IOP\#6

JIANG Haiyan, GE Runsheng and ZHU Xiaoyan

The Results of Different Cumulus Parameterizations in the Rainstorm Process

Simulation

YUEN lek Chong, HAO I Pan, KU Chi Meng and Antonio VISEU

\section{Torrential Rain}

The System Distribution and the Circulation Features of the Rainstorms during the South China Rainstorm Experiment in 1998

WANG Yongming, SU Baixing and CHANG Yue

A Synoptic Study of Heavy Rainfall over Taiwan

Chia-Chung $Y U$

Short-term Rainfall Forecasts Using the Regional Spectral Model (RSM):

Performance and Verification

W. K. WONG, H. LAM, C. C. LAM and C. K. CHOW

A Study of Heavy Precipitation in Taiwan during the Mei-yu Season

Koung-Ying LIU and Pei-Chen CHANG

Preliminary Analysis of Ground-Based GPS Observations in Huanan

Torrential Rainfall Experiment

XU Baoxiang, ZHOU Xiuji, LI Yanxing, HE Ping, WANG Rong and SONG Chunmei

Preliminary Performance Evaluation of a Rainstorm Nowcasting System

Edwin S. T. LAI and P. W. LI

\section{Air Pollution}

Emission Inventory of Civil Aircrafts over Taiwan

Po-Shiung LIN, Wei-So SUN and Jen-Ping CHEN

Numerical Simulation of the Seasonal Variation of Troposphere Ozone and

Future Scenario Forecast in China

YANG Jian, LI Weiliang and Zhou Xiuji

Author Index 